\title{
The crossover of burnout and work engagement among working couples
}

\author{
Arnold B. Bakker, Evangelia Demerouti and \\ Wilmar B. Schaufeli
}

ABSTRACT The present study tested the hypothesis that burnout and work engagement may crossover from husbands to wives and vice versa. Data were collected among 323 couples working in a variety of occupations. The Job Demands-Resources model was used to simultaneously examine possible correlates of burnout and engagement for each partner separately. The results of a series of hierarchical regression analyses provide evidence for the crossover of burnout (exhaustion and cynicism) and work engagement (vigor and dedication) among partners. The crossover relationships were significant and about equally strong for both partners, after controlling for some important characteristics of the work and home environment. These findings expand previous crossover research, particularly by showing that positive experiences at work may be transferred to the home domain. We argue that the crossover of positive feelings among partners should be placed more prominently on the research agenda.

KEYWORDS

burnout - crossover - Job Demands-Resources model - work engagement

People rarely succeed in segregating stress arising at the workplace from the family domain. Nearly two decades ago, Pearlin and Turner (1987) found that many of the participants in their study tried to prevent interference of work with family life, because they believed that their stress would anguish 
their spouse or that their spouse would blame them for their problems. However, their spouses indicated they could tell when their partners were stressed, regardless of whether or not the partner was explicit about it. Mood changes, shifts in activities or other clues focused the attention on their partners' distress, even when they did not know the reason for it. These earlier findings indicate that attempts at segmentation between work and family are rarely successful, at least as far as distress is concerned (see also Westman, 2001, for a recent overview).

Most previous crossover studies have examined the transference of negative emotions. Seligman and Csikszentmihalyi (2000) have recently stated that, to date, psychology has been preoccupied with the 'worst things in life' (p. 6) and they argue that researchers should also focus on 'positive qualities' (p. 6). One central aim of the present study is to examine, in addition to the crossover of burnout, whether work engagement may crossover from husbands to wives and vice versa. We will use the Job Demands-Resources model (Demerouti et al., 2001) to examine possible correlates of burnout and engagement for each partner separately, and test crossover effects after controlling for important characteristics of the work and home environment.

\section{The crossover process}

The process that occurs when a stressor or psychological strain experienced by one person affects the level of strain of another person is referred to as crossover (Westman, 2001), transmission (Jones \& Fletcher, 1993; Rook et al., 1991), or emotional contagion (Hatfield et al., 1994). Crossover is a dyadic, inter-individual transmission of stress or strain that occurs within a particular domain such as the workplace or the family. The recent review of Westman (2001) documents the accumulating evidence for this psychological phenomenon. More specifically, researchers have shown that the following strains may crossover from one person to another: anxiety (Westman et al., 2004a), burnout (Bakker \& Schaufeli, 2000; Bakker et al., 2001, 2003b; Pavett, 1986; Westman \& Etzion, 1995, 1999), depression (Katz et al., 1999; Vinokur et al., 1996; Westman \& Vinokur, 1998), dissatisfaction (Westman et al., 2004b), and physical health (Jones \& Fletcher, 1993). Note that the majority of these studies investigated the crossover of negative emotions and attitudes. As far as we know, the only study that investigated the crossover of positive emotions at work is the study of Bakker (2005). He hypothesized and found that intrinsic motivation, enjoyment and absorption (being totally immersed in the activity) transferred from music teachers to their students. 
Note, however, that this type of crossover is not the same as crossover between spouses.

Generally, it is assumed that the emotions expressed by one partner elicit an empathic reaction in the other partner. This agrees with the literal root meaning of the word empathy: 'feeling into'. Starcevic and Piontek (1997) define empathy as interpersonal communication that is predominantly emotional in nature and involves the ability to be affected by the other's affective state, as well as to be able to read in oneself what that affect has been. Similarly, Lazarus (1991) defined empathy as 'sharing another's feelings by placing oneself psychologically in that person's circumstances' (p. 287). The core relational theme for empathy would involve the sharing of another person's emotional state, distressed or otherwise. Accordingly, strain in one partner may produce an empathic reaction in the other, which - in its turn - increases the receiver's strain.

Social learning theorists (e.g. Bandura, 1997; Stotland, 1969) support this view, and have explained the transmission of emotions as a conscious processing of information. They suggest that individuals imagine how they would feel in the position of another and thus come to experience and share the other's feelings. It is important to note that the approaches that attempt to explain crossover, transmission or contagion assume that the crossover process is similar for negative and positive attitudes and emotions. In other words, although research has almost exclusively focused on negative emotions, from a theoretical perspective positive emotions may be expected to crossover as well.

\section{Burnout and work engagement}

Employees who are burned-out lack the energy to work adequately and poorly identify with their work. Usually, they have been over-exposed to work-related stressors, and experience feelings of exhaustion. In order to cope with this stress, they developed a distant, negative attitude towards work (cynicism) and/or towards the people with whom they work (depersonalization; Maslach et al., 2001). Originally, Maslach and her colleagues (Maslach \& Jackson, 1986; Schaufeli et al., 1996) also included reduced professional efficacy (or lack of personal accomplishment) in their definition of burnout. However, during the past decade, evidence has accumulated on the divergent role that lack of professional efficacy plays as compared to exhaustion and cynicism (e.g. Lee \& Ashforth, 1996; Leiter, 1993). More specifically, it seems that exhaustion and cynicism constitute the essence or 'core' of the burnout syndrome (Green et al., 1991; Maslach et al., 2001; Schaufeli \& Buunk, 2003). 
Recently, burnout research expanded to include its presumed opposite - work engagement (Maslach \& Leiter, 1997; Schaufeli \& Bakker, 2004). There are two different schools of thought on the relationship between burnout and engagement. Maslach and Leiter assume that burnout and engagement are two opposite poles of one continuum. They rephrased burnout as an erosion of engagement with the job, whereby energy turns into exhaustion, involvement turns into cynicism, and efficacy turns into ineffectiveness. Thus, in their view, engagement is characterized by energy, involvement and professional efficacy, which are the direct (perfectly inversely related) opposites of the three burnout dimensions. Consequently, low scores on the exhaustion and cynicism scales and high scores on the professional efficacy scale of the Maslach Burnout Inventory - General Survey (MBI GS; Maslach et al., 1996) would be indicative for engagement.

The second school of thought agrees with the assertion that work engagement is the positive antithesis of burnout, but defines and operationalizes engagement in its own right (Schaufeli \& Bakker, 2001, 2004). A separate operationalization of work engagement enables an investigation of situations in which employees are low (or high) on both burnout and engagement. For example, it is conceivable that employees in certain low demand-low responsibility jobs are not burned-out, but this does not necessarily mean that they are highly involved in their work (engaged). Thus, instead of being mutually exclusive states, burnout and engagement are principally considered to be independent states. Yet, it is expected that, empirically speaking they are moderately high and negatively related.

Engagement is defined as a positive, fulfilling, work-related state of mind that is characterized by vigor, dedication, and absorption (Schaufeli et al., 2002b). Vigor refers to high levels of energy and mental resilience while working, the willingness to invest effort in one's work, and persistence also in the face of difficulties. Dedication refers to a sense of significance, enthusiasm, inspiration, pride, and challenge. Vigor and dedication are the direct positive opposites of exhaustion and cynicism, respectively. The third dimension of engagement is called absorption, which was found to be another constituting element of engagement in 30 in-depth interviews (Schaufeli et al., 2001). Absorption is characterized by being fully concentrated and happily engrossed in one's work, whereby time passes quickly and one has difficulties with detaching oneself from work. High scores on the vigor, dedication and absorption scales of the Utrecht Work Engagement Scale (UWES - Schaufeli et al., 2002b) are indicative for work engagement. In the present study, we will focus on the core dimensions of burnout, exhaustion and cynicism, and their conceptual opposites, vigor and dedication. 


\section{Concomitants of burnout and engagement}

Several authors have argued that burnout results from a misfit between job demands and job resources (e.g. Cordes \& Dougherty, 1993; Lee \& Ashforth, 1996; Maslach \& Leiter, 1997; Schaufeli \& Enzmann, 1998). Indeed, recent studies among employees from a wide range of occupations provide strong evidence for such a Job Demands-Resources model (e.g. Bakker et al., 2003a, 2003c; Demerouti et al., 2001). Moreover, these studies suggest a specific pattern of relationships between characteristics of the working environment and the different burnout components. Job demands (such as work overload and demanding clients) are most strongly and positively related to feelings of exhaustion (as compared to the two other components), whereas job resources (such as social support, job control, and performance feedback) are most strongly and negatively related to cynicism. Importantly, these relationships were found using self-reports and independent observer ratings of the working environment (Demerouti et al., 2001).

In sharp contrast to burnout, work engagement seems to be particularly the result of the resources available in the organization. Job resources refer to those physical, psychological, social, or organizational aspects of the job that are either/or: 1) functional in achieving work goals; 2) reduce job demands and the associated physiological and psychological costs; 3) stimulate personal growth and development. Job resources have motivational potential because they make employees' work meaningful, hold them responsible for work processes and outcomes, and provide them with information about the actual results of their work activities (cf. Bakker et al., 2003c; Hackman \& Oldham, 1980).

To date, only one study directly examined the antecedents of work engagement and burnout simultaneously. Schaufeli and Bakker (2004) used structural equation modeling to concurrently analyze data from four independent occupational groups (total $N=1698$ ). Participants were working for an insurance company, an occupational health and safety service, a pension fund company, and a home-care institution. Results confirmed the authors' hypotheses indicating that burnout and engagement are not simply each other's opposite, but instead share between 10 and 25 percent of their variances. In addition, the study showed that job demands were the most important predictors of burnout (lack of resources was somewhat less important), whereas job resources (performance feedback, social support from colleagues, and supervisory coaching) were the only predictors of work engagement. 


\section{The present study}

In short, previous research has clearly shown that high job demands and low job resources form the breeding ground for burnout (for a meta analysis, see Lee \& Ashforth, 1996), whereas recent studies confirm that particularly job resources may foster work engagement. In the present study, we will use the Job Demands-Resources (JD-R) model as a guiding framework, since it has proven to be a general, overarching model that can be applied to many different occupations and organizations (e.g. Bakker et al., 2003a, 2003c; Demerouti et al., 2001). Also, the JD-R model seems to be relevant for the work-family nexus (Bakker \& Geurts, 2004). The present crossover study goes one step further by examining whether psychological demands and resources at home - in addition to job demands and resources - may have independent relationships with burnout and engagement as well.

In the literature, there is little evidence on the potential direct impact of home demands and resources on employee well-being, although previous research on family-work conflict strongly suggests that such a relationship exists (see Geurts \& Demerouti, 2003, for a review). One of the few notable exceptions is a study by Parasuraman et al. (1992), among dual-earner couples, which indicated that both men and women with pre-school children had more trouble combining work and family roles than the 'dinky's (double income no kids)'. Another example is a recent study by Peeters et al. (2005), among a heterogeneous sample of over 1000 employees, which showed that quantitative home demands, emotional home demands and mental home demands were positively related to burnout (exhaustion and cynicism), also after controlling for several job demands. In another study among newspaper managers, Montgomery et al. (2003) found that only mental home demands were positively related to cynicism (but not to exhaustion), whereas social support from family and friends (a home resource) was unrelated to burnout and work engagement. However, the sample of this latter study was rather small $(N=69)$ and data were collected only from the newspaper managers, and not from their spouses.

The central aim of the present study is to examine whether burnout and work engagement may crossover from husband to wives and vice versa, after controlling for the impact of the receiver's own demands and resources at home and at work. Research on the symptomatology of burnout has shown that the syndrome may manifest itself in various ways. Schaufeli and Enzmann (1998) counted more than 100 burnout symptoms in the literature, including such highly visible symptoms as hyperactivity, physical fatigue, and enhanced irritability. Moreover, researchers have identified several 'social symptoms' of burnout, most notably negative attitudes toward 
clients and towards one's work (see also Schaufeli \& Enzmann, 1998, for an overview). Such negative attitudes may take the form of reduced empathy, cynicism, black humor, withdrawal, and stereotyping. Because of the explicit nature of many burnout symptoms they may easily be observed by one's spouse and are therefore likely to be transferred, particularly when socializing at home. For example, a husband who is repeatedly exposed to cynical remarks about clients made by his wife, may develop feelings of cynicism when these remarks remind him of the times that his own clients were extremely demanding (cf. Bakker et al., in press). Hence, we formulate the following two hypotheses (one for each receiver):

Hypothesis 1a: Husbands' levels of burnout (exhaustion and cynicism) are positively related to their wives' levels of burnout, after controlling for the impact of wives' job and home demands as well as job and home resources.

Hypothesis 1b: Wives' levels of burnout (exhaustion and cynicism) are positively related to their husbands' levels of burnout, after controlling for the impact of husbands' job and home demands as well as job and home resources.

Although previous crossover research has usually focused on and found evidence for the crossover of negative (work-related) states, it is well conceivable that work engagement may crossover as well. Schaufeli et al. (2001) interviewed 30 employees, and found that engaged workers are generally optimistic, take personal initiative and are proud of their work. Several interviewees indicated that they took the initiative to increase skill variety in their jobs. Moreover, because of their positive attitudes and pro-active behaviors, they generated their own rewards and positive feedback in terms of appreciation, support and admiration. Engaged workers are highly dedicated to their work and the organization they work for, and are inclined to help their colleagues if needed (organizational citizenship behavior, Organ \& Paine, 1999). This may create a positive spiral of success (Llorens et al., in press), which is communicated to others in the working environment and at home. Thus, work engagement may be transferred to spouses with different jobs in different work environments if the vigor and dedication expressed by the partners elicit enthusiasm about one's own work, either in a conscious or an unconscious way.

More specifically, there are at least three reasons why work engagement may crossover between partners. First, since work engagement is the positive antithesis of burnout (see González-Romá et al., in press), we may 
expect a direct empathic crossover process that 'mirrors' the burnout crossover effect. Thus, just like burnout, work engagement may crossover from husbands to wives (and vice versa) during interpersonal communication, because wives place themselves psychologically in their husbands' circumstances (Lazarus, 1991; Starcevic \& Piontek, 1997). Second, experimental studies have convincingly shown that positive emotions can crossover from one person to another through an 'automatic' process of emotional contagion (for an overview, see Hatfield et al., 1994). This makes work engagement a good candidate for crossover as well. Third, recent research (Bakker \& Geurts, 2004) has shown that positive work-related states (e.g. intrinsic motivation and work-related happiness) have a positive influence on private life, as employees come home cheerfully after a successful day at work. This means that if a husband comes home during a working day in a positive state, he is, for instance, more willing to take care of household responsibilities, giving his wife opportunities for recovery - a prerequisite for her work engagement during the next day (Sonnentag, 2003). Hence, our next hypotheses address the crossover of work engagement:

Hypothesis 2a: Husbands' levels of work engagement (vigor and dedication) are positively related to their wives' levels of engagement, after controlling for the impact of wives' job and home demands as well as job and home resources.

Hypothesis 2a: Wives' levels of work engagement (vigor and dedication) are positively related to their husbands' levels of engagement, after controlling for the impact of husbands' job and home demands as well as job and home resources.

\section{Method}

\section{Procedure and participants}

The study was carried out among a convenience sample of Dutch dual-earner couples. In order to ensure that both partners were employed, participants were recruited through the kindergarten where they brought their child(ren). In total, 12 different kindergartens participated in the study. Research assistants distributed envelopes with two identical questionnaires (one for each partner) and a cover letter at the entrance of the kindergarten. The questionnaires were code-numbered to match the partners afterwards, and the letter explained the goal of the study. Participation was voluntary, and it was explained that the data would be treated anonymously and confidentially. 
Each partner was kindly requested to fill out the questionnaire separately. In total, 323 couples participated in the study. Unfortunately, the response rate could not be calculated, because it was not administrated how many parents were approached in the 12 kindergartens. Respondents returned their own and their partner's questionnaires in closed envelopes through a special box placed in a central position at the entrance of the kindergarten. Participants were employed in a range of different occupations (e.g. managers, doctors, teachers, salespersons, software engineers), and there were some differences between men and women. Men were about two years older than women (Men $M=35.92, \mathrm{SD}=6.65$; Women $M=34.03$, $\mathrm{SD}=6.27), t(322)=9.20$, $p<.001$, and had somewhat more work experience $(\mathrm{Men} M=12.94, \mathrm{SD}=$ 6.91; Women $M=11.23$, SD = 6.34), $t(322)=3.28, p<.001$. In addition, men more often occupied a leadership position than women $(45 \%$ versus $21 \%)$. However, although men and women were employed in different occupations - for example, more men than women in business and finances $(31 \%$; Women 24\%), and more women than men in health care (34\%; Men $12 \%)$ - there were no differences in educational level. For the group as a whole, the level of education was quite high: lower-level high school, 7.5 percent, higher-level high school, 24 percent, college education, 68 percent, and otherwise, 0.5 percent. Furthermore, the differentiation between working with people, things, or information (cf. Fine \& Cronshaw, 1999) showed that there were generally no significant differences regarding the type of work men and women performed, $\chi 2(6)=8.01$, NS. Most participants $(71 \%)$ worked predominantly with people; 22 percent worked with information, and 7 percent worked with things. All couples had at least one child; the majority $(64 \%)$ had one or more children between 0 and 3 years of age, and 36 percent had one or more children between 4 and 12 years of age.

\section{Measures}

\section{Job demands}

Work overload was assessed with a three-item scale developed by Bakker et al. (2003d). The items refer to quantitative, demanding aspects of the job. An example item is: 'My job requires working very hard'. Items are scored on a five-point frequency scale, ranging from 1) 'never' to 5) 'always'. Unless otherwise indicated, all following demands and resources used the same response categories. Internal consistencies (Cronbach's alpha) of all scales are displayed in Table 1. Emotional demands were assessed with the five-item scale proposed by Bakker et al. (2003c). An example item is: 'Do you face emotionally charged situations in your work?' Cognitive demands refer to 
the degree to which work tasks call upon you to expend sustained mental effort in carrying out your duties. They were assessed by a four-item scale developed by Peeters et al. (2005). An example item is: 'Does your work require high concentration?' An explorative factor analysis on the cognitive demands items resulted in a clear one-factor solution, explaining 57 percent of the variance for men, and 63 percent of the variance for women. All items had factor loadings $>.58$ for husbands and factor loadings $>.66$ for wives. This indicates that the items formed a homogeneous factor.

\section{Job resources}

Two job resources developed by Bakker et al. (2003c) were included in the questionnaire. Autonomy was measured with three items particularly referring to decision authority (i.e. freedom of action in accomplishing the formal work task). An example item is: 'Can you decide yourself how you execute your work?'. Social support from colleagues was also assessed with a threeitem scale, including: 'Can you ask your colleagues for help if necessary?'

\section{Home demands}

Three home demands developed by Montgomery et al. (2003) were included in the questionnaire, namely home overload, emotional demands, and cognitive demands. The scales conceptually mirror the subscales of the job demands scales. Thus, the home demands instrument consisted of a home overload scale (five items; e.g. 'Do you find that you are busy at home?'), an emotional home demands scale (three items; e.g. 'How often do emotional issues arise at home?'), and a cognitive home demands scale (three items; e.g. 'Do you find that you have to plan and organize a lot of things in relation to your home life?').

\section{Home resources}

Two home resources were included, namely home autonomy and social support. These two home resources were developed by the researchers and conceptually mirror the subscales of the job resources scales. Several scholars have successfully used a job-related measure as a model for constructing a symmetrical home-related measure (e.g. Frone et al., 1992; Parasuraman et al., 1992). Home autonomy was assessed with four items, including 'I have control over how I use my free time'. Home social support was also measured with four items, including 'My partner/family help(s) me with a certain task if necessary'. An exploratory factor analysis with subsequent varimax 
rotation on the eight items assessing both home resources resulted in a clear two-factor solution for both men and women. The explained variance in home social support and home control was 35 percent and 26 percent for men, and 35 percent and 27 percent for women, respectively.

\section{Burnout}

The two core dimensions of burnout, exhaustion and cynicism, were assessed with subscales of the Dutch version (Schaufeli \& Van Dierendonck, 2000) of the Maslach Burnout Inventory - General Survey (Schaufeli et al., 1996). The exhaustion scale includes five items that refer to severe fatigue. Example items are: 'I feel used up at the end of the workday', and 'I feel burned out from work'. Cynicism reflects indifference or a distant attitude towards work, and is measured with four of the five items from the original scale. Item 4 ('I just want to do my job and not be bothered') was omitted, as suggested by Schaufeli and Van Dierendonck (2000) and Schutte et al. (2000) because it proved to be unsound. An example item is: 'I have become more cynical about whether my work contributes anything'. The items of both subscales were scored on a seven-point rating scale $(0=$ never, $6=$ always $)$.

\section{Work engagement}

The two core dimensions of work engagement - vigor and dedication - were measured with the Utrecht Work Engagement Scale (Schaufeli et al., 2002a, 2002b). Example items of the five-item Vigor scale are: 'At my job, I feel bursting with energy', and 'When I get up in the morning, I feel like going to work'. Examples of the five-item Dedication scale are: 'My job inspires me', and 'I am enthusiastic about my job'. Items were rated on a seven-point scale ranging from 0 'never' to 6 'always'.

\section{Results}

\section{Descriptive statistics}

Table 1 shows the means, standard deviations, and the internal consistencies (Cronbach's alpha) of the scales included in the analyses, for men and women separately. As can be seen from this table, all scales save two exceptions show acceptable reliabilities with values of Cronbach's alpha exceeding .70. Home emotional demands for men and cynicism for women had a reliability coefficient of .68. Furthermore, there were small but significant differences between men and women regarding most variables. Men reported higher 
Table I Means, standard deviations and reliability coefficients for all study variables, for men $(N=323)$ and women $(N=323)$

\begin{tabular}{|c|c|c|c|c|c|c|c|c|}
\hline & \multirow[t]{2}{*}{ Variable } & \multicolumn{3}{|l|}{ Men } & \multicolumn{3}{|c|}{ Women } & \multirow[t]{2}{*}{$t$} \\
\hline & & Mean & $S D$ & Alpha & Mean & $S D$ & Alpha & \\
\hline I & Work overload & 3.23 & .75 & .82 & 3.05 & .85 & .86 & $3.08 *$ \\
\hline 2 & Work emotional demands & 1.98 & .57 & .80 & 2.14 & .63 & .81 & $-3.66 * *$ \\
\hline 3 & Work cognitive demands & 3.75 & .64 & .77 & 3.62 & .70 & .80 & $3.01 *$ \\
\hline 4 & Work autonomy & 3.91 & .73 & .79 & 3.67 & .75 & .75 & $4.25 * *$ \\
\hline 5 & Work social support & 3.49 & .84 & .75 & 3.54 & .92 & .84 & $<1$ \\
\hline 6 & Home overload & 2.70 & .50 & .78 & 3.11 & .51 & .77 & $-11.87 * *$ \\
\hline 7 & Home emotional demands & 2.15 & .63 & .68 & 2.22 & .65 & .74 & -1.62 \\
\hline 8 & Home cognitive demands & 2.44 & .75 & .79 & 2.97 & .95 & .87 & $-9.16 * *$ \\
\hline 9 & Home autonomy & 3.13 & .58 & .77 & 3.37 & .61 & .72 & $-5.37^{* *}$ \\
\hline 10 & Home social support & 3.24 & .97 & .84 & 3.11 & .83 & .83 & 1.94 \\
\hline II & Exhaustion & 1.51 & .87 & .83 & 1.76 & 1.00 & .83 & $-3.82 * *$ \\
\hline 12 & Cynicism & 1.62 & .99 & .76 & 1.82 & 1.00 & .68 & $-2.76^{*}$ \\
\hline 13 & Vigor & 4.13 & .84 & .81 & 4.03 & .83 & .80 & 1.63 \\
\hline 14 & Dedication & 4.25 & 1.01 & .85 & 4.04 & 1.10 & .84 & $2.66 *$ \\
\hline
\end{tabular}


work overload and higher cognitive demands than women, whereas women reported higher emotional demands at work. Most likely, the latter reflects the fact that more women than men work in caring professions. In addition, and in accordance with traditional sex-role patterns, women scored consistently higher than men on home overload, home cognitive demands, and home autonomy. Women also reported higher levels of burnout (exhaustion and cynicism), and a lower level of dedication to work. This suggests that if we find evidence for the crossover of burnout and work engagement between partners, it cannot be attributed to the fact that men and women are attracted to and marry partners who share a similar level of well-being.

Table 2 displays the correlations between all study variables for men and women separately, as well as the 'crossover' correlations (e.g. the correlation between men's work overload and women's work overload; on the diagonal). The highest crossover correlation $(r=.45)$ was observed for emotional demands at home. Preliminary analyses revealed that demographic variables (age, educational level, organizational tenure, type of work, number of children) were neither substantially, nor consistently (across the genders) related to the burnout and engagement dimensions, and these were therefore omitted from further analyses.

\section{Crossover of burnout}

According to Hypothesis 1a, husbands' levels of burnout (exhaustion and cynicism) are positively related to their wives' levels of burnout, also after controlling for the impact of job and home demands as well as job and home resources. Hypothesis $1 \mathrm{~b}$ stated that the same would be true for the crossover of burnout from wives to their husbands. To test both hypotheses, we conducted two hierarchical regression analyses for both genders separately. Each analysis used the following five-step regression model: job demands (step 1), job resources (step 2), home demands (step 3), home resources (step 4), partner's burnout (step 5). These analyses thus test the crossover of both burnout components from husbands to wives, and vice versa. Despite its elegant possibilities to test crossover effects, we decided not to use structural equation modeling in this study. The reason for this is the relatively large number of variables included in our research model.

Table 3 displays the results of the regression of husbands' exhaustion and cynicism on their job demands and resources, home demands and resources, and their wives' exhaustion and cynicism. Since regression coefficients may not be stable and change with different samples and with addition or subtraction of independent variables to the analysis (Kerlinger \& Lee, 2000), the results should be interpreted with some caution. We 
Table 2 Correlations between the variables (crossover on the diagonal), $N=323$ couples

\begin{tabular}{|c|c|c|c|c|c|c|c|c|c|c|c|c|c|c|c|}
\hline & & 1 & 2 & 3 & 4 & 5 & 6 & 7 & 8 & 9 & 10 & 11 & 12 & 13 & 14 \\
\hline I & Work overload & $.14^{*}$ & $.39 * *$ & $.45 * *$ & .06 & .05 & .08 & .04 & .08 & -.02 & -.04 & $.22 * *$ & .08 & $.16 * *$ & $.19 * *$ \\
\hline 2 & Work emotional demands & $.29 * *$ & $.20 * *$ & $.37 * *$ & -.03 & -.07 & .04 & $.22 * *$ & .08 & -.09 & -.06 & $.30 * *$ & $.15^{* *}$ & -.06 & .06 \\
\hline 3 & Work cognitive demands & $.42^{* *}$ & $.23 * *$ & $.27^{* *}$ & $.15^{* *}$ & $.20 * *$ & .06 & .06 & .07 & $.12^{*}$ & .00 & $.17 * *$ & $-.12^{*}$ & $.24 * *$ & $.31 * *$ \\
\hline 4 & Work autonomy & .10 & $-.15^{* *}$ & $\overline{.03}$ & $.12 *$ & $.19 * *$ & .01 & -.05 & .08 & $.11 *$ & .08 & $-.20 * *$ & $-.15 * *$ & $.30 * *$ & $.33^{* *}$ \\
\hline 5 & Work social support & .08 & -.10 & $.14 *$ & $.11 *$ & $.22 * *$ & $-.15^{* *}$ & $-.15 * *$ & $-.14 *$ & $.27^{* *}$ & $.20 * *$ & $-.25^{* *}$ & $-.30 * *$ & $.34^{* *}$ & $.36 * *$ \\
\hline 6 & Home overload & .03 & .01 & .08 & -.07 & .05 & $.25 * *$ & $.36 * *$ & $.58 * *$ & $-.15^{* *}$ & $-.14 * *$ & $.28^{* *}$ & .09 & $-.11 *$ & -.08 \\
\hline 7 & Home emotional demands & .01 & $.14 *$ & $.14^{*}$ & -.08 & .05 & $.30 * *$ & $\underline{.45^{* *}}$ & $.39 * *$ & $-.26 * *$ & -.01 & $.24 * *$ & $.18^{* *}$ & $-.19 * *$ & $-.15^{* *}$ \\
\hline 8 & Home cognitive demands & .04 & .09 & .10 & .00 & .06 & $.63 * *$ & $.33^{* *}$ & $.26 * *$ & $-.16 * *$ & -.10 & .10 & .03 & .00 & .06 \\
\hline 9 & Home autonomy & -.04 & .02 & -.06 & .07 & .11 & $-.28 * *$ & $-.23 * *$ & $-.27 * *$ & .07 & $.27^{* *}$ & $-.15^{* *}$ & $-.15^{* *}$ & $.22 * *$ & $.21^{* *}$ \\
\hline 10 & Home social support & .00 & .00 & .02 & .06 & $.21^{* *}$ & -.05 & -.09 & -.03 & $.29 * *$ & $.12 *$ & $-.14 *$ & -.10 & $.22 * *$ & $.17^{* *}$ \\
\hline II & Exhaustion & .09 & $.30 * *$ & .01 & -.22 & $-.18^{* *}$ & $.14 *$ & $.22 * *$ & .00 & $-.13 *$ & -.06 & $\underline{.20}$ ** & $.52^{* *}$ & $-.44 * *$ & $-.30^{* *}$ \\
\hline 12 & Cynicism & .05 & $.25 * *$ & -.08 & $-.27^{* *}$ & $-.2 I^{* *}$ & .06 & $.19 * *$ & .03 & -.05 & -.01 & $.56 * *$ & $.16^{* *}$ & $-.46^{* *}$ & $-.57^{* *}$ \\
\hline 13 & Vigor & $.16 * *$ & -.06 & $.19 * *$ & $.24 * *$ & $.20 * *$ & -.06 & -.03 & -.05 & $.18^{* * *}$ & $.18^{* *}$ & $-.36 * *$ & $-\overline{-.43} * *$ & $.17^{* *}$ & $.74 * *$ \\
\hline 14 & Dedication & $.13 *$ & -.09 & $.27^{* *}$ & $.24 * *$ & $.20 * *$ & .01 & -.04 & .02 & .03 & $.13^{*}$ & $-.33^{* *}$ & $-.57^{* *}$ & .73 ** & $.13^{*}$ \\
\hline
\end{tabular}

Note. Husbands' correlations are displayed under the diagonal, and wives' correlations above the diagonal. The crossover correlations are underlined.

$* * p<.01, * p<.05$. 
Table 3 Regression of husbands' burnout on their job demands and resources, home demands and resources, and wives' burnout, $N=323$ couples

\begin{tabular}{|c|c|c|c|c|c|c|c|c|c|c|c|}
\hline \multirow[t]{2}{*}{ Step } & \multirow[t]{2}{*}{ Model } & \multicolumn{5}{|c|}{ Exhaustion } & \multicolumn{5}{|c|}{ Cynicism } \\
\hline & & $B$ & S.E. & $\beta$ & $R^{2}$ change & $F$ change & $B$ & S.E. & $\beta$ & $R^{2}$ change & F change \\
\hline \multirow[t]{3}{*}{ I } & Work overload & .10 & .07 & .08 & & & .14 & .08 & .10 & & \\
\hline & Work emotional demands & .38 & .09 & $.25^{* * *}$ & & & .32 & .10 & $.19 * * *$ & & \\
\hline & Work cognitive demands & -.13 & .08 & -.10 & .09 & $1 \mathrm{I} .0 \mathrm{I} * * *$ & -.24 & .09 & $-.16 * *$ & .08 & $9.68 * * *$ \\
\hline \multirow[t]{2}{*}{2} & Work autonomy & -.15 & .06 & $-.12^{*}$ & & & -.27 & .07 & $-.20 * * *$ & & \\
\hline & Work social support & -.12 & .06 & $-.11 *$ & .05 & $8.57^{* * * *}$ & -.19 & .06 & $-.16 * *$ & .07 & $13.69 * * *$ \\
\hline \multirow[t]{3}{*}{3} & Home overload & .30 & $.1 \mathrm{I}$ & $.17 * *$ & & & .06 & .13 & .03 & & \\
\hline & Home emotional demands & .25 & .08 & $.18 * * * *$ & & & .29 & .09 & $.19 * * *$ & & \\
\hline & Home cognitive demands & -.23 & .08 & $-.20 * *$ & .06 & $8.34 * * *$ & -.06 & .09 & -.05 & .03 & $4.16 * *$ \\
\hline \multirow[t]{2}{*}{4} & Home autonomy & -.12 & .08 & -.08 & & & -.03 & .10 & -.02 & & \\
\hline & Home social support & .01 & .05 & .02 & .00 & $<1$ & .05 & .06 & .05 & .00 & $<1$ \\
\hline \multirow[t]{3}{*}{5} & Wives' burnout' & .13 & .04 & $.15^{* *}$ & .02 & $8.25 * *$ & .14 & .05 & $.14 * *$ & .02 & $7.74 * *$ \\
\hline & Constant & 1.26 & .56 & & & & 2.24 & .64 & & & \\
\hline & Total $\mathrm{R}^{2}$ & & & & .22 & & & & & .20 & \\
\hline
\end{tabular}

Note. ' It should be noted that wives' exhaustion is the predictor of husbands' exhaustion; and that wives' cynicism is the predictor of husbands' cynicism. $* * * * 0.001$, ** $p<.01, * p<.05$. 
provide both standardized and unstandardized regression coefficients. As can be seen in the lower part of Table 3, wives' exhaustion significantly and uniquely predicts husbands' exhaustion, and wives' cynicism significantly and uniquely predicts husbands' cynicism, after controlling for the influence of the work and home environment. These findings corroborate Hypothesis 1a. Note also that emotional work demands and all home demands were significant predictors of husbands' exhaustion. Furthermore, in addition to wives' cynicism, all job demands (except work overload) and resources, as well as home emotional demands predicted husbands' cynicism.

Table 4 shows the results of the regressions of wives' burnout on their husbands' burnout, controlling simultaneously for job and home demands, and for resources. Consistent with Hypothesis $1 \mathrm{~b}$, husbands' exhaustion significantly and uniquely predicts wives' level of exhaustion. In addition, unlike most home demands and resources, most job demands and resources also contribute to explaining variance in wives' exhaustion. Furthermore, husbands' cynicism significantly predicts wives' levels of cynicism, although this is also influenced by cognitive work demands and social support at work. Taken together, these findings confirm Hypothesis $1 \mathrm{a}$ and $1 \mathrm{~b}$, showing that there is a bi-directional crossover of burnout (exhaustion and cynicism) from husbands to wives as well as from wives to husbands.

\section{Crossover of work engagement}

According to Hypothesis 2a, husbands' levels of work engagement (vigor and dedication) are positively related to their wives' levels of work engagement, also after controlling for the impact of job and home demands as well as job and home resources. According to Hypothesis $2 \mathrm{~b}$, the same is predicted for the crossover of engagement from wives to their husbands. To test these hypotheses, we followed a similar approach as for burnout, and carried out four separate stepwise hierarchical regression analyses, subsequently including a person's own job demands (step 1), job resources (step 2), home demands (step 3), and home resources (step 4), and the partner's work engagement (step 5). Hence, these analyses test the crossover of both engagement components from husbands to wives and vice versa.

Table 5 displays the results of the regression of husbands' vigor and dedication on job demands and resources, home demands and resources, and wives' levels of vigor and dedication. As can be seen in the bottom row of this table, wives' vigor significantly and uniquely predicts their husbands' levels of vigor, whereas wives' dedication significantly and uniquely predicts husbands' level of dedication, also after controlling for the influence of the working environment, as well as the demands and resources at home. These 
Table 4 Regression of wives' burnout on their job demands and resources, home demands and resources, and husbands' burnout, $N=323$ couples

\begin{tabular}{|c|c|c|c|c|c|c|c|c|c|c|c|}
\hline \multirow[t]{2}{*}{ Step } & \multirow[t]{2}{*}{ Model } & \multicolumn{5}{|c|}{ Exhaustion } & \multicolumn{5}{|c|}{ Cynicism } \\
\hline & & $B$ & S.E. & $\beta$ & $R^{2}$ change & $F$ change & $B$ & S.E. & $\beta$ & $R^{2}$ change & F change \\
\hline \multirow[t]{3}{*}{ I } & Work overload & .11 & .07 & .09 & & & .12 & .07 & .10 & & \\
\hline & Work emotional demands & .24 & .09 & $.15^{* *}$ & & & .18 & .10 & .12 & & \\
\hline & Work cognitive demands & .18 & .08 & $.13^{*}$ & .10 & $11.92 * * *$ & -.22 & .09 & $-.15^{*}$ & .07 & $7.56 * * *$ \\
\hline \multirow[t]{2}{*}{2} & Work autonomy & -.20 & .07 & $-.15^{* *}$ & & & -.09 & .07 & -.06 & & \\
\hline & Work social support & -.21 & .06 & $-.19 * * *$ & .09 & $18.16 * * * *$ & -.26 & .06 & $-.24 * * *$ & .07 & $13.05^{* * * k}$ \\
\hline \multirow[t]{3}{*}{3} & Home overload & .53 & .12 & $.27^{* * *}$ & & & .13 & .13 & .07 & & \\
\hline & Home emotional demands & .14 & .09 & .09 & & & .18 & .09 & .12 & & \\
\hline & Home cognitive demands & -.16 & .07 & $-.15^{*}$ & .07 & $9.78 * * *$ & -.11 & .07 & -.10 & .02 & 2.51 \\
\hline \multirow[t]{2}{*}{4} & Home autonomy & -.05 & .09 & -.03 & & & -.01 & .10 & -.01 & & \\
\hline & Home social support & -.04 & .06 & -.03 & .00 & $<1$ & -.04 & .07 & -.03 & .00 & $<1$ \\
\hline \multirow[t]{3}{*}{5} & Husbands' burnout' & .14 & .06 & $.12^{*}$ & .01 & $6.06 *$ & .13 & .05 & $.12^{*}$ & .01 & $5.44 *$ \\
\hline & Constant & .34 & .57 & & & & 2.56 & .61 & & & \\
\hline & Total $\mathrm{R}^{2}$ & & & & .27 & & & & & .17 & \\
\hline
\end{tabular}

Note. ' It should be noted that husbands' exhaustion is the predictor of wives' exhaustion; and that husbands' cynicism is the predictor of wives' cynicism. $* * * * 001$, *** $p<.01, * p<.05$. 
Table 5 Regression of husbands' work engagement on their job demands and resources, home demands and resources, and wives' work engagement, $N=323$ couples

\begin{tabular}{|c|c|c|c|c|c|c|c|c|c|c|c|}
\hline \multirow[t]{2}{*}{ Step } & \multirow[t]{2}{*}{ Model } & \multicolumn{5}{|l|}{ Vigor } & \multicolumn{5}{|c|}{ Dedication } \\
\hline & & B & S.E. & $\beta$ & $R^{2}$ change & $F$ change & B & S.E. & $\beta$ & $R^{2}$ change & $F$ change \\
\hline \multirow[t]{3}{*}{ I } & Work overload & .11 & .07 & .10 & & & .02 & .08 & .02 & & \\
\hline & Work emotional demands & -.14 & .08 & -.10 & & & -.21 & .10 & $-.12^{*}$ & & \\
\hline & Work cognitive demands & .20 & .08 & $.16^{* *}$ & .06 & $7.25 * * *$ & .42 & .09 & $.27^{* * * *}$ & .10 & $11.58^{* * *}$ \\
\hline \multirow[t]{2}{*}{2} & Work autonomy & .20 & .06 & $.17^{* *}$ & & & .26 & .07 & $.18 * * *$ & & \\
\hline & Work social support & .10 & .06 & .10 & .06 & $11.05 * * * *$ & .11 & .07 & .09 & .06 & $10.36 * * *$ \\
\hline \multirow[t]{3}{*}{3} & Home overload & .01 & .11 & .01 & & & .01 & .14 & .00 & & \\
\hline & Home emotional demands & .04 & .08 & .03 & & & -.07 & .09 & -.04 & & \\
\hline & Home cognitive demands & -.04 & .08 & -.03 & .00 & $<1$ & .02 & .09 & .01 & .00 & $<1$ \\
\hline \multirow[t]{2}{*}{4} & Home autonomy & .20 & .08 & $.14^{*}$ & & & .00 & .10 & .00 & & \\
\hline & Home social support & .10 & .05 & $.11 *$ & .03 & $5.92 * *$ & .11 & .06 & .10 & .01 & 1.28 \\
\hline \multirow[t]{3}{*}{5} & Wives' engagement $^{1}$ & .13 & .05 & $.13^{*}$ & .02 & $6.15^{*}$ & .11 & .05 & $.12^{*}$ & .01 & $5.35^{*}$ \\
\hline & Constant & .70 & .59 & & & & .91 & .69 & & & \\
\hline & Total $\mathrm{R}^{2}$ & & & & .17 & & & & & .18 & \\
\hline
\end{tabular}

Note. ' It should be noted that wives' vigor is the predictor of husbands' vigor; and that wives' dedication is the predictor of husbands' dedication. *** $p<.001, * * p<.01, * p<.05$. 
findings corroborate Hypothesis 2a. Note that cognitive work demands and work autonomy, as well as both home resources significantly predict husbands' level of vigor. Furthermore, in addition to wives' dedication, emotional and cognitive work demands, as well as work autonomy predict husbands' dedication (none of the home characteristics is significant).

Finally, Table 6 shows the results of the regressions of wives' work engagement on their husbands' level of engagement, controlling simultaneously for job and home demands and resources. Consistent with Hypothesis $2 \mathrm{~b}$, husbands' vigor significantly and uniquely predicts their wives' level of vigor. In addition, several work and home characteristics contribute to explaining variance in wives' vigor. Furthermore, husbands' dedication significantly predicts their wives' level of dedication, even though this is also influenced by cognitive work demands, work autonomy and social support at work, as well as by emotional and cognitive home demands and social support at home. Taken together, these findings confirm Hypothesis $2 \mathrm{a}$ and $2 \mathrm{~b}$, showing that there is a bi-directional crossover of work engagement (vigor and dedication) from husbands to their wives and vice versa.

\section{Discussion}

The central aim of the present study was to examine whether burnout and work engagement may crossover from husbands to wives and vice versa. We used the Job Demands-Resources model (Bakker et al., 2003a; Demerouti et al., 2001) to examine possible correlates of burnout and engagement for each partner separately, and tested crossover effects after controlling for potential demands and resources in the work and the home environment. The results of a series of hierarchical regression analyses indeed suggest bi-directional crossover of burnout and work engagement among working couples. The magnitude of the negative (burnout) crossover effects was similar to that of the positive (engagement) crossover effect.

These findings replicate and expand previous crossover research in four important ways. First, although we did not incorporate everything that might commonly affect husbands and wives into the analyses, we controlled for several demands and resources at home in an attempt to rule out common stressors and resources as a spurious cause of crossover (cf. Westman \& Vinokur, 1998). Common environmental factors affecting both partners may impact the strain (or engagement) of both and the positive correlation detected between the strains (engagement) of the spouses will appear to be due to a crossover effect. Interestingly, the results showed that the demands (overload, emotional demands, and cognitive demands) and resources 
Table 6 Regression of wives' work engagement on their job demands and resources, home demands and resources, and husbands' work engagement, $N=323$ couples

\begin{tabular}{|c|c|c|c|c|c|c|c|c|c|c|c|}
\hline \multirow[t]{2}{*}{ Step } & \multirow[t]{2}{*}{ Model } & \multicolumn{5}{|l|}{ Vigor } & \multicolumn{5}{|c|}{ Dedication } \\
\hline & & B & S.E. & $\beta$ & $R^{2}$ change & F change & B & S.E. & $\beta$ & $R^{2}$ change & $F$ change \\
\hline \multirow[t]{3}{*}{ I } & Work overload & .13 & .05 & $.13^{*}$ & & & .11 & .07 & .09 & & \\
\hline & Work emotional demands & -.14 & .07 & -.10 & & & .04 & .10 & .02 & & \\
\hline & Work cognitive demands & .18 & .07 & $.15 * *$ & .10 & $\left.11.1\right|^{* * *}$ & .28 & .09 & $.18^{* *}$ & .11 & $12.56 * * *$ \\
\hline \multirow[t]{2}{*}{2} & Work autonomy & .21 & .06 & $.19 * * * k$ & & & .31 & .07 & $.21 * * *$ & & \\
\hline & Work social support & .18 & .05 & $.20 * * *$ & .12 & $25.12 * * *$ & .29 & .06 & $.24 * * *$ & .14 & $30.52^{* * * *}$ \\
\hline \multirow[t]{3}{*}{3} & Home overload & -.17 & .10 & -.11 & & & -.22 & .13 & -.10 & & \\
\hline & Home emotional demands & -.18 & .07 & $-.14^{*}$ & & & -.22 & .09 & $-.13^{*}$ & & \\
\hline & Home cognitive demands & .13 & .05 & $.15^{*}$ & .03 & $3.93 * *$ & .21 & .07 & $.18^{* * *}$ & .03 & $4.47^{* *}$ \\
\hline \multirow[t]{2}{*}{4} & Home autonomy & .04 & .07 & .03 & & & .10 & .10 & .06 & & \\
\hline & Home social support & .16 & .05 & $.16^{* *}$ & .03 & $5.43 * *$ & .13 & .07 & $.10^{*}$ & .01 & 2.98 \\
\hline \multirow[t]{3}{*}{5} & Husbands' engagement ${ }^{1}$ & .15 & .05 & $.15^{* *}$ & .02 & $9.13 * *$ & .13 & .05 & $.12 *$ & .01 & $6.33^{*}$ \\
\hline & Constant & 1.20 & .49 & & & & -.32 & .65 & & & \\
\hline & Total $R^{2}$ & & & & .30 & & & & & .30 & \\
\hline
\end{tabular}

Note. ' It should be noted that husbands' vigor is the predictor of wives' vigor; and that husbands' dedication is the predictor of wives' dedication.

$* * * * 001, * * p<.01, * p<.05$. 
(autonomy, social support) at home were different for husbands and wives, as was apparent from the low correlations between them. Thus, their significance to each member of the couple was different. We can conclude that the crossover paths did not result from a similar home situation of both partners, at least as far as the home demands and resources are concerned that were included in our study. Nevertheless, it is conceivable that other factors that were not included, such as financial problems, problems in children's education, and the recent death of a relative might be responsible for the couple's covariation of their mental states. Therefore, future studies might include such factors as well.

Second, previous studies were restricted to the crossover of (physical, cognitive and emotional) exhaustion (e.g. Westman \& Etzion, 1995), whereas this study examined the crossover of both exhaustion and cynicism. Both were tapped with the most widely used instrument to assess burnout the Maslach Burnout Inventory (Maslach et al., 2001). Thus, our study shows that not only negative affect (feeling exhausted), but also negative attitudes towards work (cynicism) may be transferred from husbands to wives and vice versa. This suggests that cynical remarks about clients made by husbands (wives) influence wives' (husbands') attitudes towards their work and clients. In other words, our study is the first to demonstrate crossover of both core components of burnout.

Third, this study is one of the first attempts to examine the crossover of positive work-related feelings and attitudes - i.e. work engagement. Positive emotions are not merely the absence of stress but qualitatively different experiences (Fredrickson, 2001; Schaufeli \& Bakker, 2004). So far, most crossover researchers have limited their analyses to negative experiences at work such as job stress and burnout (for an overview, see Westman, 2001). Results of our study reveal that positive feelings of energy (vigor) and enthusiasm (dedication) expressed by one partner influence the other partner, even after controlling for relevant aspects of the work and home environment. This suggests a process whereby one partner who feels engaged as a result of the resources available at work (cf. Schaufeli \& Bakker, 2004), is likely to express this engagement towards the partner. The partner, in turn, is influenced by this positive state of mind and starts feeling the same way. These findings are consistent with the results of Bakker's (2005) study among music teachers and their students, on the crossover of work-related flow. He hypothesized and found that peak experiences of intrinsic work motivation, work enjoyment and absorption transferred from teachers to their students. On a critical note, one might argue that men and women are attracted to (and marry) partners who share a similar level of work engagement, and this would explain a positive crossover effect of engagement. However, this 
alternative explanation does need seem to hold for the present findings, since women scored significantly lower on dedication (and higher on exhaustion and cynicism).

Finally, most crossover studies examined only unidirectional processes from husbands to their wives, and did not investigate wives' work-related experiences affecting their husband (Westman, 2001). Our findings with a relatively large and heterogeneous sample of highly educated working couples show that there is hardly any difference between the crossover of burnout and engagement from husbands to wives and vice versa, thus confirming bi-directional crossover. This is consistent with the results of some other studies that did investigate bi-directional crossover. For example, Hammer et al. (1997), in their study among dual-earner couples, found evidence for bi-directional crossover of work-family conflict. In a similar vein, Gareis et al. (2003), in a study among 105 female reduced-hours physicians and their full-time-employed husbands, found that husbands' ratings of their own work schedule fit predicted wives' marital-role quality; and wives' ratings of own schedule fit predicted husbands' psychological distress. In line with these studies, our analysis highlights the importance of being cautious in drawing firm conclusions regarding the moderating effects of gender (i.e. differential crossover effects from husbands to wives than from wives to husbands), because gender may be confounded with breadwinner role in the family and/or with a traditional gender and power relationship. Westman et al. (2004) have argued that researchers should address this issue by collecting more specific information on the breadwinning roles, occupation and work status of both spouses, as well as on the extent to which they hold traditional gender ideologies.

\section{Two possible crossover processes}

The current study should be seen as a first attempt to test whether experiences of work engagement may crossover. Future studies should aim at replication, and may expand the current study by investigating the possible processes responsible for crossover. In general, it is assumed that the emotions expressed by one partner elicit an empathic reaction in the other partner. Sharing the partner's feelings by placing oneself psychologically in the other's work circumstances may indeed have been responsible for the crossover of work engagement. Levy et al. (2002) maintain that perceiving similarity between oneself and others can lead one to take the others' perspectives thus prompting experience of empathic emotions (empathic identification; see also Keinan et al., 2003). Other factors that may facilitate the crossover of burnout and engagement are frequency of emotional 
expression, and susceptibility to the emotions of others (see Bakker \& Schaufeli, 2000; Bakker et al., 2001).

However, the crossover process may also include the automatic imitation of a cheerful and happy partner. Several field and experimental studies have shown that positive and negative emotions may crossover from one person to another (for an overview, see Hatfield et al., 1994). For example, an experiment of Lanzetta et al. (1985), in which individuals were filmed and questioned while they were watching a speech of President Reagan, showed that supporters shared his enjoyment when he was telling something happy, and reported tension when he was telling something fearful. Although opponents reported negative feelings during the whole speech, their facial expressions were congruent with those of Reagan. In addition, assessments of their galvanic skin responses showed that both supporters and opponents were more relaxed during the happy messages than during the disturbing announcements.

\section{The Job Demands-Resources model}

The Job Demands-Resources model (Bakker et al., 2003a, 2003c; Demerouti et al., 2001) was used as a heuristic framework for the examination of job and home demands, and resources. Consistent with previous research, we found that particularly demands were related to exhaustion (Demerouti et al., 2001), whereas resources were most strongly related to work engagement (Schaufeli \& Bakker, 2004). These findings point at the two different processes proposed by the model, namely a stress process, starting with high demands leading to increased feelings of exhaustion for both partners; and a motivational process, starting with high resources and leading to vigor and dedication of both partners. In addition, our model was successfully expanded to the home domain, and it was used from two perspectives namely from both partners.

Interestingly, results showed that home characteristics may influence work-related experiences of burnout and engagement as well, although to a lesser extent than job demands and resources. Home demands (particularly emotional demands) predicted men's and women's feelings of exhaustion; emotional demands at home were only predictive of men's cynicism (not wives'). This suggests that home demands may exacerbate feelings of burnout, independent of the work environment. Remember that we found the highest 'crossover' relationship for emotional demands at home $(r=.45$, $p<.01)$. This means that men and women generally agreed regarding the demanding nature of emotions at home. In contrast, home resources were more important for the prediction of work engagement, although emotional 
demands at home also reduced wives' vigor and dedication. Such relationships have been described as spillover (Geurts \& Demerouti, 2003), referring to the transference of characteristics of one domain (home) to the other (work).

Finally, cognitive demands at home and at work played an unexpected role. Both types of cognitive demands refer to the degree to which tasks call upon individuals to expend sustained mental effort in carrying out duties (e.g. high concentration, careful planning and coordination, continuous attention). Results showed that mental demands in both domains were negatively related to burnout and positively related to work engagement. We can only speculate about the reasons for these unexpected findings. It is conceivable that the cognitive demands at work reported by our participants were experienced as being challenging, and therefore reduced feelings of burnout and stimulated work engagement. This is all the more likely since we investigated a fairly highly educated group working in complex and challenging jobs such as lawyers, doctors, and engineers. However, why would cognitive demands at home be related in a similar way to both experiences? It suggests that those who organize many things at home simultaneously are also often concentrated at work. Future studies on this spillover phenomenon should examine possible reasons for this.

\section{Limitations}

The present study is not without limitations. First, we used a convenience sample, which questions the generalizability of the findings. Although we used a heterogeneous sample, the fact that our participants were highly educated and had considerable home responsibilities (all couples had at least one child) questions whether we may generalize our findings to other groups, for example individuals with a lower education and families without children (or with grown-up children). In addition, although each partner was kindly requested to fill out the questionnaire separately, we cannot be entirely sure whether the couples really filled out the questionnaires alone. If partners completed the questionnaires jointly, this may contribute to greater crossover. Thus, future studies are needed to test whether the findings can be replicated in other, more representative samples. A second limitation concerns the fact that we only used self-report questionnaires. Common method bias may thus have influenced some of the results. It would be interesting to also use other-ratings in future crossover research to avoid this problem. Third, it should be noted that the partners' level of burnout and work engagement could only explain a meager 1-2 percent of the variance in burnout and work engagement. Apparently, job demands and resources 
are the most important predictors of both types of experiences at work. Finally, our study did not include an examination of the processes responsible for crossover effects, and included only a few demands and resources as control variables. Specifically, although we controlled for autonomy and social support while examining the crossover of work engagement, there are definitely other resources that can predict engagement (see Brown, 1996). We therefore suggest that future crossover studies should include additional (work and person-related) predictors of engagement as control variables.

\section{Final note}

The present study confirms that attempts at segmentation between work and family are rarely successful (see Westman, 2001). Whereas previous studies had shown that people rarely succeed in segregating stress arising in the workplace from the family domain, the current study suggests that positive experiences are also not limited to one domain. The findings suggest that engagement at work may also crossover to the family domain, and have a positive impact on the partner's well-being. We agree with Westman that the crossover of positive feelings among partners should be placed more prominently on the research agenda, and that future studies should focus on the mechanisms explaining such a crossover. Partners within close relationships may utilize knowledge on this topic such that they get a better insight in their own and their partner's feelings, attitudes, and behaviors at work. Finally, organizations may utilize the knowledge on crossover between partners such that they can create working conditions and provide resources to their employees that enhance the positive experiences at work and at home since they are mutually related. Since recent research suggests that work engagement has positive consequences for both individuals (Sonnentag, 2003), and organizations (Schaufeli \& Bakker, 2004), the current findings further emphasize the relevance of work engagement as a concept in the domain of positive organizational behavior.

\section{References}

Bakker, A.B. Flow among music teachers and their students: The crossover of peak experiences. Journal of Vocational Behavior, 2005, 66, 26-44.

Bakker, A.B., Demerouti, E., De Boer, E. \& Schaufeli, W.B. Job demands and job resources as predictors of absence duration and frequency. Journal of Vocational Behavior, 2003a, $62,341-56$.

Bakker, A.B., Demerouti, E. \& Schaufeli, W.B. The socially induced burnout model. In S.P. 
Shohov (Ed.), Advances in psychology research, Vol. 25. New York: Nova Science Publishers, 2003b, pp. 13-30.

Bakker, A.B., Demerouti, E. \& Schaufeli, W.B. Dual processes at work in a call centre: An application of the Job Demands-Resources model. European Journal of Work and Organizational Psychology, 2003c, 12, 393-417.

Bakker, A.B., Demerouti, E., Taris, T., Schaufeli, W.B. \& Schreurs, P. A multi-group analysis of the Job Demands-Resources model in four home care organizations. International Journal of Stress Management, 2003d, 10, 16-38.

Bakker, A.B. \& Geurts, S. Toward a dual-process model of work-home interference. Work \& Occupations, 2004, 31, 345-66.

Bakker, A.B., Le Blanc, P.M. \& Schaufeli, W.B. Burnout contagion among intensive care nurses. Journal of Advanced Nursing, in press.

Bakker, A.B. \& Schaufeli, W.B. Burnout contagion processes among teachers. Journal of Applied Social Psychology, 2000, 30, 2289-308.

Bakker, A.B., Schaufeli, W.B., Sixma, H. \& Bosveld, W. Burnout contagion among general practitioners. Journal of Social and Clinical Psychology, 2001, 20, 82-98.

Bandura, A. Self-efficacy: The exercise of control. New York: Freeman, 1997.

Brown, S.P. A meta-analysis and review of organizational research on job involvement. Psychological Bulletin, 1996, 120, 235-55.

Cordes, C.L. \& Dougherty, T.W. A review and integration of research on job burnout. Academy of Management Review, 1993, 18, 621-56.

Demerouti E., Bakker, A.B., Nachreiner, F. \& Schaufeli, W.B. The job demands-resources model of burnout. Journal of Applied Psychology, 2001, 86, 499-512.

Fine, S.A. \& Cronshaw, S.F. Functional job analysis: A foundation for buman resources management. Mahwah, NJ: Lawrence Erlbaum, 1999.

Fredrickson, B. The role of positive emotions in positive psychology: The broaden-andbuild theory of positive emotions. American Psychologist, 2001, 56, 218-26.

Frone, M.R., Russell, M. \& Cooper, M.L. Antecedents and outcomes of work-family conflict: Testing a model of the work-family interface. Journal of Applied Psychology, 1992, 77, 65-78.

Gareis, K.C., Barnett, R.C. \& Brennan, R.T. Individual and crossover effects of work schedule fit: A within-couple analysis. Journal of Marriage and Family, 2003, 65, 1041-54.

Geurts, S.A.E. \& Demerouti, E. The work-home interface: State-of-the-art and future research agenda. In M. Schabracq, J. Winnubst \& C.L. Cooper (Eds), Handbook of work and health psychology. Chichester: Wiley, 2003, pp. 279-312.

González-Romá, V., Schaufeli, W.B., Bakker A.B. \& Lloret, S. Burnout and work engagement: Independent factors or opposite poles? Journal of Vocational Behavior, in press.

Green, D.E., Walkey, F.H. \& Taylor, A.J.W. The three-factor structure of the Maslach Burnout Inventory. Journal of Social Behavior \& Personality, 1991, 6, 453-72.

Hackman, J.R. \& Oldham, G.R. Work redesign. Reading, MA: Addison-Wesley, 1980.

Hammer, L.B., Allen, E. \& Grigsby, T.D. Work-family conflict in dual-earner couples: Within individual and crossover effects of work and family. Journal of Vocational Behavior, 1997, 50, 185-203.

Hatfield, E., Cacioppo, J. \& Rapson, R. Emotional contagion. New York: Cambridge University Press, 1994.

Jones, F. \& Fletcher, B. Transmission of occupational stress: A study of daily fluctuations in work stress and strain and their impact on marital partners. In H. Schroder, K. Rescke, M. Johnston \& S. Maes (Eds), Health psychology: Potential indiversity. Regensburg: Roderer Verlag, 1993, pp. 328-38.

Katz, J., Beach, S. \& Joiner, T. Contagious depression in dating couples. Journal of Social and Clinical Psychology, 1999, 18, 1-13.

Keinan, G., Sadeh, A. \& Rosen, S. Attitudes and reaction to media coverage on terrorist acts. Journal of Community Psychology, 2003, 31, 149-68. 
Kerlinger, F.N. \& Lee, H.B. Foundations of behavioral research, 4th edn. Stamford, CT: Wadsworth, 2000.

Lanzetta, J.T., Sullivan, D.G., Masters, R.D. \& Mchugo, G.J. Viewers' emotional and cognitive responses to televised images of political leaders. In S. Kraus \& R. Perloff (Eds), Mass media and political thought. Beverly Hills, CA: Sage, 1985, pp. 85-116.

Lazarus, R.S. Emotion and adaptation. New York: Oxford, 1991.

Lee, R.T. \& Ashforth, B.E. A meta-analytic examination of the correlates of the three dimensions of job burnout. Journal of Applied Psychology, 1996, 81, 123-33.

Leiter, M.P. Burnout as a developmental process: Consideration of models. In W.B. Schaufeli, C. Maslach \& T. Marek (Eds), Professional burnout: Recent developments in theory and research. Washington, DC: Taylor \& Francis, 1993, pp. 237-50.

Levy, S., Freitas, A. \& Salovey, P. Construing actions abstractly and blurring social distinctions: Implications for perceiving homogeneity among, but also empathizing with helping others. Journal of Personality and Social Psychology, 2002, 83, 1224-38.

Llorens, S., Salanova, M., Bakker, A.B. \& Schaufeli, W.B. Does a positive gain spiral of resources, efficacy beliefs and engagement exist? Computers in Human Behavior, in press.

Maslach, C. \& Jackson, S.E. Maslach Burnout Inventory, 2nd edn. Palo Alto, CA: Consulting Psychologists Press, 1986.

Maslach, C., Jackson, S.E. \& Leiter, M.P. Maslach Burnout Inventory. Manual, 3rd edn. Palo Alto, CA: Consulting Psychologists Press, 1996.

Maslach, C. \& Leiter, M.P. The truth about burnout: How organizations cause personal stress and what to do about it. San Francisco, CA: Jossey-Bass, 1997.

Maslach, C., Schaufeli, W.B. \& Leiter, M.P. Job burnout. Annual Review of Psychology, 2001, 52, 397-422.

Montgomery, A.J., Peeters, M.C.W., Schaufeli, W.B. \& Den Ouden, M. Work-home interference among newspaper managers: Its relationship with burnout and engagement. Anxiety, Stress \& Coping, 2003, 16, 195-211.

Organ D.W. \& Paine, J.B. A new kind of performance for industrial and organizational psychology: Recent contributions to the study of organizational citizenship behavior. In C.L. Cooper \& I.T. Robertson (Eds), International review of industrial and organizational psychology, Vol. 14. Chichester: Wiley, 1999, pp. 337-68.

Parasuraman, S., Purohit, Y.S. \& Godschalk, V.M. Role stressors, social support and wellbeing among two-career couples. Journal of Organizational Behavior, 1992, 13, 339-56.

Pavett, C.M. High-stress professions: Satisfaction, stress, and well-being of spouses of professionals. Human Relations, 1986, 39, 1141-54.

Pearlin, L.I. \& Turner, H.A. The family as a context of the stress process. In S.V. Kasl \& C. Cooper (Eds), Stress and health: Issues in research methodology. New York: Wiley, 1987, pp. 143-65.

Peeters, M.C.W., Montgomery, A., Bakker, A.B. \& Schaufeli, W.B. Balancing work and home: How job and home demands are related to burnout. International Journal of Stress Management, 2005, 12, 43-61.

Rook, S.K., Dooley, D. \& Catalano, R. Stress transmission: The effects of husbands' job stressors on emotional health of their wives. Journal of Marriage and the Family, 1991, $53,165-77$.

Schaufeli, W.B. \& Bakker, A.B. Werk en welbevinden: Naar een positieve benadering in de Arbeids- en Gezondheidspsychologie [Work and well-being: Towards a positive occupational health psychology]. Gedrag \& Organisatie, 2001, 14, 229-53.

Schaufeli, W.B. \& Bakker, A.B. Job demands, job resources, and their relationship with burnout and engagement: A multi-sample study. Journal of Organizational Behavior, 2004, 25, 293-315.

Schaufeli, W.B. \& Buunk, B.P. Burnout: An overview of 25 years of research and theorizing. In M.J. Schabracq, J.A.M. Winnubst \& C.L. Cooper (Eds), Handbook of work and health psychology. Chichester: Wiley, 2003, pp. 383-425. 
Schaufeli, W.B. \& Enzmann, D. The burnout companion to study and practice: A critical analysis. London: Taylor \& Francis, 1998.

Schaufeli, W.B., Leiter, M.P., Maslach, C. \& Jackson, S.E. The Maslach Burnout Inventory - General Survey. In C. Maslach, S.E. Jackson \& M.P. Leiter (Eds), Maslach Burnout Inventory. Manual, 3rd edn. Palo Alto, CA: Consulting Psychologists Press, 1996.

Schaufeli, W.B., Martinez, I., Marques Pinto, A., Salanova, M. \& Bakker, A.B. Burnout and engagement in university students: A cross-national study. Journal of CrossCultural Psychology, 2002a, 33, 464-81.

Schaufeli, W.B., Salanova, M., González-Romá, V. \& Bakker, A.B. The measurement of engagement and burnout: A confirmative analytic approach. Journal of Happiness Studies, 2002b, 3, 71-92.

Schaufeli, W.B., Taris, T., Le Blanc, P., Peeters, M., Bakker, A.B. \& De Jonge, J. Maakt arbeid gezond? Op zoek naar de bevlogen werknemer [Does work cause health? The quest for the engaged worker]. De Psycholoog, 2001, 36, 422-8.

Schaufeli, W.B. \& Van Dierendonck, D. De UBOS, Utrechtse Burnout Schaal. Handleiding [The UBOS, Utrecht Burnout Scale. Manual]. Lisse, The Netherlands: Swets Test Services, 2000.

Schutte, N., Toppinnen, S., Kalimo, R. \& Schaufeli, W.B. The factorial validity of the Maslach Burnout Inventory - General Survey (MBI - GS) across nations and occupations. Journal of Occupational and Organizational Psychology, 2000, 73, 53-66.

Seligman, M.E.P. \& Csikszentmihalyi, M. Positive psychology: An introduction. American Psychologist, 2000, 55, 5-14.

Sonnentag, S. Recovery, work engagement, and proactive behavior. A new look at the interface between non-work and work. Journal of Applied Psychology, 2003, 88, 518-28.

Starcevic, V. \& Piontek, C.M. Empathic understanding revisited: Conceptualization, controversies, and limitations. American Journal of Psychotherapy, 1997, 51, 317-28.

Stotland, E. Exploratory investigations of empathy. In L. Berkowitz (Ed.), Advances in experimental social psychology, Vol. 4. New York: Academic Press, 1969, pp. 271-314.

Vinokur, A., Price, R.H. \& Caplan, R.D. Hard times and hurtful partners: How financial strain affects depression and relationship satisfaction of unemployed persons and their spouses. Journal of Personality and Social Psychology, 1996, 71, 166-79.

Westman, M. Stress and strain crossover. Human Relations, 2001, 54, 557-91.

Westman, M. \& Etzion, D. Crossover of stress, strain and resources from one spouse to another. Journal of Organizational Behavior, 1995, 16, 169-81.

Westman, M. \& Etzion, D. The crossover of strain from school principals to teachers and vice versa. Journal of Occupational Health Psychology, 1999, 4, 269-78.

Westman, M., Etzion, D. \& Horovitz, S. The toll of unemployment does not stop with the unemployed. Human Relations, 2004a, 57, 823-44.

Westman, M. \& Vinokur, A. Unraveling the relationship of distress levels within couples: Common stressors, emphatic reactions, or crossover via social interactions? Human Relations, 1998, 51, 137-56.

Westman, M., Vinokur, A.D., Hamilton, V.L. \& Roziner, I. Crossover of marital dissatisfaction during downsizing: A study of Russian army officers and their spouses. Journal of Applied Psychology, 2004b, 89, 769-79. 
Arnold B. Bakker is full Professor of Positive Organizational Behavior at Utrecht University, The Netherlands, and a member of the Research Institute Psychology \& Health. He received his $\mathrm{PhD}$ in social psychology from the University of Groningen. His research interests include positive organizational psychology (e.g. flow and engagement at work, performance), burnout, crossover of work-related emotions, and internet applications of organizational psychology. His research has been published in journals such as Journal of Applied Psychology, Journal of Vocational Behavior, and Human Resource Management.

[E-mail: A.Bakker@fss.uu.nl]

Evangelia Demerouti is Assistant Professor of Social and Organizational Psychology at Utrecht University, The Netherlands. She received her PhD in burnout from Oldenburg University, Germany. Her main research interests concern topics from the field of work and health, including the Job Demands-Resources model, burnout, work-family interface, crossover of strain, flexible working times, shift-work, and job design. Her articles have been published in journals including Journal of Vocational Behavior, Journal of Management, and Journal of Applied Psychology.

[E-mail: E.Demerouti@fss.uu.nl]

Wilmar B. Schaufeli is full Professor of Occupational Health Psychology at Utrecht University, The Netherlands. He is scientific director of the Research Institute Psychology \& Health in which six Dutch and two Belgian universities participate. He received his $\mathrm{PhD}$, cum laude, in clinical psychology from the University of Groningen. His research interests include job stress, burnout, absenteeism, work engagement, workaholism, and worksite health interventions.

[E-mail:W.Schaufeli@fss.uu.nl, Internet: www.schaufeli.com] 